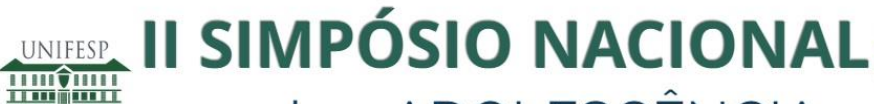 sobre ADOLESCÊNCIA: Vulnerabilidades, Protagonismos e Desafios
}

\section{Associação entre a Dependência de Internet e transtornos mentais}

\author{
Adriana Scatena \\ Universidade Federal de São Paulo \\ André Luiz Monezi Andrade \\ Universidade Anhembi Morumbi \\ Universidade Federal de São Paulo \\ André Bedendo \\ Universidade Federal de São Paulo \\ Denise de Micheli \\ Universidade Federal de São Paulo
}

\section{Como citar:}

Scatena, Adriana et al. Associação entre a Dependência de Internet e transtornos mentais. In: II SIMPÓSIO NACIONAL SOBRE ADOLESCÊNCIA: VULNERABILIDADE, PROTAGONISMOS E DESAFIOS, 2. 2016, São Paulo. Anais...[S.I]: 2016. p. 55.

DOI: http://dx.doi.org/10.22388/2525-5894.2016.034

Introdução: a dependência de internet é um fenômeno cada vais mais comum em diversos países, parte disso em decorrência da relação estabelecida dos indivíduos com novas tecnologias. De forma geral, os países asiáticos possuem os maiores índices de dependentes em comparação a outras nações. Diversos trabalhos apontam uma relação entre a dependência de internet e o desenvolvimento de transtornos mentais, especialmente os transtornos de ansiedade e de humor. No Brasil, contudo, existem poucos estudos avaliando o efeito da dependência de internet em relação aos aspectos emocionais, especialmente em estudantes. Objetivos: avaliar a dependência digital em uma amostra de estudantes universitários e sua possível associação com a depressão, estresse e ansiedade.

Métodos: participaram da pesquisa 5986 estudantes a partir de um link disponibilizado na internet para o preenchimento virtual. Os estudantes preencheram o Internet Addiction Test (IAT) com o objetivo de avaliar o padrão de uso de internet, além de um questionário socioeconômico desenvolvido pelos autores composto por 8 questões gerais (gênero, estado, estado civil, idade, número de filhos, curso de graduação, semestre e tipo de universidade) e 15 questões específicas acerca sobre o padrão de uso das mídias digitais. Além disso, os estudantes preencheram o questionário DASS-21 com o objetivo de avaliar os níveis de depressão, ansiedade e estresse.

Resultados: observou-se que 1948 (32,5\%) estudantes foram classificados pelo IAT como Usuários Sem Risco (Grupo USR), 56,8\% como Usuários de Baixo Risco (Grupo UBR) e 10,7\% como Usuários de Risco e Alto Risco (Grupo URAR). Em relação à depressão aproximadamente5\% do grupo USR apresentou um quadro grave de sintomas depressivos e no grupo URAR observou-se uma prevalência em $34 \%$ da amostra $(p<0,01)$. Em relação à ansiedade a quantidade de estudantes que apresentaram um quadro grave de 
ansiedade foi quase 5 vezes maior no grupo URAR em comparação aos estudantes que não apresentavam problemas de dependência de internet. Em relação ao estresse $34 \%$ dos estudantes do grupo URAR apresentavam níveis graves de estresse em comparação com aqueles que não possuíam problemas $(6,4 \%)$. Conclusões: os dados indicam claramente uma forte associação entre a dependência de internet e o sofrimento mental, corroborando outros estudos da literatura. A dependência de internet pode levar ao empobrecimento de relações sociais e, consequentemente, ao desenvolvimento de psicopatologias. Os dados encontrados sugerem a importância de futuros programas preventivos e interventivos que tenham como foco esta população.

Palavras-chave: Dependência de internet. Estudantes. Depressão. Estresse. Ansiedade. 